\title{
Adipogenic potential of stem cells derived from rabbit subcutaneous and visceral adipose tissue in vitro
}

\author{
Ekaterina Vachkova $^{1} \cdot$ D. Bosnakovski ${ }^{2} \cdot$ P. Yonkova $^{3} \cdot$ N. Grigorova ${ }^{1} \cdot$ Zh. Ivanova $^{1}$. \\ P. Todorov ${ }^{4}$ - G. Penchev ${ }^{3}$ - A. Milanova ${ }^{1}$ - G. Simeonova ${ }^{5}$ - S. Stanilova ${ }^{6}$. \\ I. Penchev Georgiev ${ }^{1}$
}

Received: 26 January 2016 / Accepted: 22 April 2016 /Published online: 12 May 2016 / Editor: Tetsuji Okamoto

(C) The Society for In Vitro Biology 2016

\begin{abstract}
Rabbits are considered as appropriate animal models to study some obesity-associated abnormalities because of the similarity of their blood lipid profile and metabolism to humans. The current study was focused on comparison of adipose differentiation ability in rabbit adipose-derived stem cells (ADSC) in vitro. Subcutaneous and visceral stromal vascular fractions (SVF) were isolated from three 28-d-old New Zealand rabbits by collagenase digestion. Supernatants from both isolates were collected $24 \mathrm{~h}$ after the initial plating. On the fourth passage, all isolated cell types undergo triplicate adipogenic induction. The adipose induction potential was calculated as percentage of increasing optical density (OD) values. The data revealed that with increasing the number of induction cycles, the induction tendency in visceral ADSC decreased in contrast to the subcutaneous ones. Although the supernatants did not reach induction levels of their relevant
\end{abstract}

Ekaterina Vachkova

katvach@gbg.bg

1 Animal Physiology Unit, Department of Pharmacology, Animal Physiology and Physiological Chemistry, Faculty of Veterinary Medicine, Trakia University, 6000 Stara Zagora, Bulgaria

2 Faculty of Medical Sciences, University Goce Delčev-Štip, Shtip, Republic of Macedonia

3 Department of Veterinary Anatomy, Histology and Embryology, Faculty of Veterinary Medicine, Trakia University, Stara Zagora, Bulgaria

4 Institute of Biology and Immunology of Reproduction, Sofia, Bulgaria

5 Department of Veterinary Surgery, Faculty of Veterinary Medicine, Trakia University, 6000 Stara Zagora, Bulgaria

6 Department of Molecular Biology, Immunology and Genetics, Faculty of Medicine, Trakia University, Stara Zagora, Bulgaria precursors, they follow the same pattern in both subcutaneous and visceral ADSC. All cell types successfully passed osteogenic and chondrogenic differentiation. In conclusion, the best adipose induction ability was observed in directly plated subcutaneous cell population. The increase of induction numbers depressed adipose induction ability in cell populations derived from visceral fat depots.

Keywords Rabbits · Subcutaneous and visceral ADSC . Supernatants $\cdot$ Adipose differentiation potential

\section{Introduction}

The obesity and obesity-related diseases have increased globally in the recent decades. Suitable animal models need to be developed to study the mechanism of these disorders. Rabbits are considered as an appropriate species in development of animal models for atherosclerosis and insulin resistance studies, because of their similarity to human blood lipid profile (Aguilera et al. 2002; Yanni 2004). Various high fat diet and interventions (as castration, for example) have been used in rabbits for induction of metabolic syndrome (MS) and its consequence disorders such as insulin resistance, visceral obesity, hypertension, and dyslipidemia (Georgiev et al. 2011; Vignozzi et al. 2011).

The main purpose of adipose tissue (AT) as a dynamic system is to store energy, and it has the ability to significantly influence the metabolic processes in the whole organism by secreting adipokins (Trayhurn and Beattie 2001; Wozniak et al. 2009; Dodson et al. 2011). Besides the mature adipocytes, several other cell types are located in the fat tissue and can be isolated by enzyme degradation following differential centrifugation. The cell fraction derived from the white adipose tissue (WAT) is defined as stromal vascular fraction 
(SVF), and majority of cells within it are actually precursors to adipocytes in adults (Rodeheffer et al. 2008; Lowe et al. 2011; Hausman and Dodson 2012). The SVF consists of a heterogeneous mesenchymal population of cells including fibroblasts, smooth muscle cells, pericytes, and endothelial cells (Katz 2002; Ailhaud 2006) but also adipose stromal cells, hematopoietic stem cells, progenitor cells, endothelial cells, erythrocytes, lymphocytes, monocyte, macrophages etc. (Mitchell et al. 2006; Han et al. 2010; Cawthorn et al. 2012). After seeding into culture, a subset of elongated cells from SVF adheres to the tissue culture plastic. Following protocols for cell expansion in culture, which are similar to those used for bone marrow mesenchymal stem cells (MSC), most of the hematopoietic cell population diminishes from the SVF cells. Due to that process, a population of adherent cells, less heterogeneous than SVF cells, is purified and termed as adiposederived stem cells (ADSC) (Rodeheffer et al. 2008; Bourin et al. 2013). These cells have multipotent properties (Zuk et al. 2002) in various species including mice, pigs, rabbits, and humans, and they can be differentiated in vitro into several lineages such as mature adipocytes (Reyne et al. 1989; Zuk et al. 2001; Tran and Kahn 2010; Lowe et al. 2011), chondrocytes, and osteoblasts (Zheng et al. 2006; Tran and Kahn 2010) or even into cardiomyocytes (Choi et al. 2012). Some authors reported that these cells proliferate at a high rate and maintain a multipotent differentiation capacity in vitro for up to 12 passages (Yang et al. 2011b).

The efforts of the scientists in the recent years have been directed to establishment of new methods for isolation of endogenous fraction of multipotent stem cells. While the traditional protocols of ADSC rely on the cell's ability to adhere to tissue culture plastic overnight, recently an additional method was described. It was implemented by seeding the floating ADSC supernatant fractions after $24 \mathrm{~h}$ of initial incubation (Buschmann et al. 2013). Comparison of adherent and supernatant fractions of ADSC resulted in similar surface protein profiles and in insignificantly different growth kinetics. The authors concluded that the floating ADSC fraction is an equivalent second cell source just like the adherent ADSC fraction. The crosstalk between subcutaneous and visceral AT in relation to development of MS and its consequence disorders on the one hand and the multipotent properties of SVF and ADSC, respectively, on the other hand make them suitable for therapy of various diseases by which those abnormalities can be modulated. Recently, Perrini et al. (2013) revealed for the first time that depending on isolation method, the functionality of achieved cells could differ widely in humans. The authors distinguish two ADSC populations in addition to the SVF - from ceiling and bottom. They report significant differences in gene expression profile and related functional networks and in the cytokine release ability of these cells respective to their anatomical origin (Perrini et al. 2013).
The current study proposes an in vitro model for defining the adipose differentiation potential of rabbit induced subcutaneous and visceral ADSC achieved from SVF. While there is scarce available information concerning adipose differentiation ability of those cells in rabbits, we aimed to discover it in relation to the isolation method, numbers of applied inductions, and adipose depot origin. Since rabbits are considered as an appropriate animal species for exploring obesity and related disorders in humans, the proposed model could contribute to the obtaining of more precise data in further studies of AT malfunctions. The additional benefits of such investigation will develop better isolation methods for future use of ADSC as a source of adult stem cell autologous therapies in animals.

\section{Materials and Methods}

Animals and cell isolation procedure The SVF were obtained from three 28-d-old New Zealand rabbits. Euthanasia was performed in accordance with the recommendations of the Local Committee for Humane Treatment of Animals. The samples, weighting approximately $1-1.5 \mathrm{~g}$ each, were collected from the subcutaneous (interscapular region) and visceral (perirenal region) fat depots, washed several times with PBS, and minced into fine pieces under sterile conditions. To release the individual cells, samples were digested with $0.5 \mathrm{mg} /$ $\mathrm{ml}$ collagenase for $2 \mathrm{~h}$ and centrifuged at $300 \mathrm{~g}$ for $10 \mathrm{~min}$. This step separated the mature lipid-filled adipocytes, which floated to the top, from the heterogeneous mixture of cells (blood cells, pericytes, endothelial cells, fibroblasts, preadipocytes, and other cells, collectively named SVF) which were in pellet from the bottom (Tang et al. 2008 with some modification). The final isolation step was seeding of the SV fraction into T25 tissue flasks in basal medium consisting of Dulbecco's Modified Eagle Medium (DMEM), 10\% fetal bovine serum (FBS), L-glutamine, and antibiotic mixed solution (penicillin G, streptomycin, amphotericin B), all from Sigma (St. Louis, MO), and incubation under humidified 5\% $\mathrm{CO}_{2}$ conditions at $38^{\circ} \mathrm{C}$ until reaching confluence. By this stage, presumably only the preadipocytes (i.e., the adipose stem cell population) were selected, by their adherence to plastic (Monaco et al. 2011). Twenty-four hours after the initial plating, the supernatants (S) were collected and re-plated for further cell expansion (Fig. 1).

Experiment design and adipogenic differentiation After initial expansion, the achieved ADSC were cultured up to passage 4 and then they were used for the experiment. The experimental groups of ADSC from subcutaneous and visceral fat depots were seeded at $5 \times 10^{4} / \mathrm{ml}$ density and cultured in 24 well plates with basal medium for $3 \mathrm{~d}$ under humidified 5\% $\mathrm{CO}_{2}$ conditions at $38^{\circ} \mathrm{C}$ until the monolayer became confluent. 
Figure 1 Schematic representation of direct seeded subcutaneous and visceral ADSC and their relevant supernatant cells. Scale bars $350 \mu \mathrm{m}$.

\section{Subcunaneus Visceral}
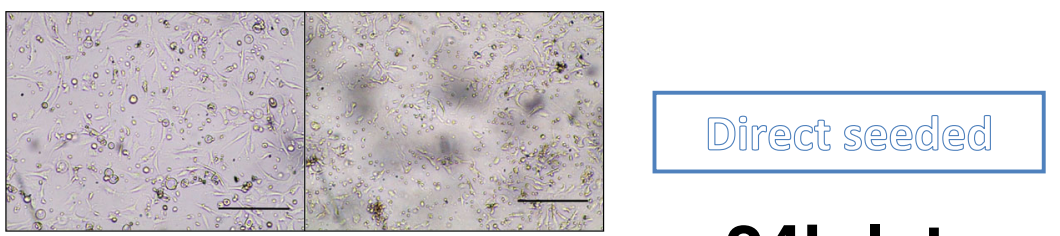

\section{4h later}

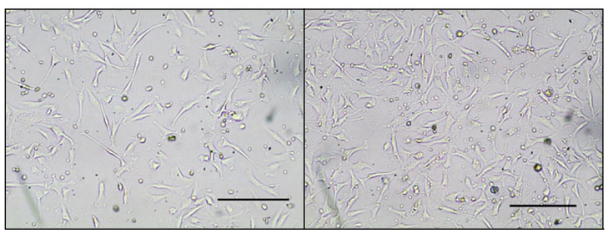

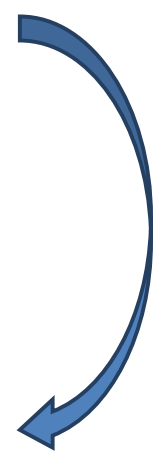

After that period, the cell cultures were harvested for an additional $24 \mathrm{~h}$ for growth arrest and treated with adipogenic induction medium (AIM) consisting of DMEM (high glucose), 10\% FBS, L-glutamine, $0.1 \mathrm{mM}$ 3-isobutyl-1-methylxanthine (IBMX), $0.05 \mathrm{mM}$ indomethacin, $1 \mu \mathrm{M}$ dexamethasone, $10 \mu \mathrm{g} / \mathrm{ml}$ insulin, and antibiotic mixed solution (penicillin $\mathrm{G}$, streptomycin, amphotericin B), all from Sigma, for $3 \mathrm{~d}$. On the third day AIM was replaced with adipogenesis maintenance medium (AMM), containing DMEM (high glucose), 10\% FBS, L-glutamine, $10 \mu \mathrm{g} / \mathrm{ml}$ insulin, and antibiotic mixed solution (penicillin G, streptomycin, amphotericin B) for an additional $3 \mathrm{~d}$. This procedure was triplicated up to Day 21 (Bosnakovski et al. 2005). In order to distinguish between the spontaneous and induced adipogenesis, an additional group of each cell type was kept in control medium containing DMEM (high glucose), 10\% FBS, L-glutamine, and antibiotic mixed solution (penicillin G, streptomycin, amphotericin B). Those cells were considered as controls and were used for further calculations to eliminate the level of spontaneous induction. Each experimental plate was duplicated.

Oil red O (ORO) staining and lipid quantification After finishing each cycle of induction/maintenance medium treatment, cells from the experimental and control groups were washed twice with PBS and fixed with $10 \%(v / v)$ neutral buffered formalin for $30 \mathrm{~min}$ at room temperature. During fixation, a fresh working solution of Oil Red O (Sigma) was prepared by mixing three parts of $0.5 \%$ Oil Red O in isopropanol stock solution with two parts of dd $\mathrm{H}_{2} \mathrm{O}$. It was kept at room temperature for $10 \mathrm{~min}$ and was filtered through filter paper (Yang et al. (2011a)) to remove the unresolved stain particles. Fixed cells were washed twice with PBS, and each well was filled up with $300 \mu \mathrm{l}$ Oil Red $\mathrm{O}$ working solution and incubated for $30 \mathrm{~min}$ at room temperature. Subsequently, the stain was removed and the wells were triple washed with distilled water. The images were taken using an inverted Telaval Carl Zeiss Jena (Jena, Germany) microscope equipped with an MDCE-5 high-resolution ocular camera (China). Immediately after the washing procedure, the wells were dried and each stained well filled with $1 \mathrm{ml} \mathrm{100 \%}$ isopropanol for $10 \mathrm{~min}$ at room temperature to extract the accumulated Oil Red O stain from the intracellular lipid droplets (LD). The optical density (OD) of collected elutes were measured at $490 \mathrm{~nm}$ using Evolution ${ }^{\mathrm{TM}} 300 \mathrm{UV}-\mathrm{Vis}$ spectrophotometer (Thermo Scientific, Waltham, Massachusetts (MA), USA). The extraction procedure was performed after each cycle of induction in both experimental and control groups. The adipose induction potential (AIP) was calculated as percentage of increasing OD values in induced and their relevant controls (considered as $100 \%$ ) for each sample by the following formula, $\mathrm{AIP} \%=[($ Induced - Contr $) \times 100] /$ Control, and the mean value for each induced group was calculated.

Additional osteogenic and chondrogenic differentiation was performed for testing the functional multipotency of the ADSC and applied to each isolated cell type.

Osteogenic differentiation After the initial expansion, the ADSC cells were seeded in 24-well plates with average density $5 \times 10^{4} / \mathrm{ml}$ and harvested in basal medium, under humidified $5 \% \mathrm{CO}_{2}$ conditions at $38^{\circ} \mathrm{C}$ until reaching confluence. After that stage, the cells were harvested for an additional $24 \mathrm{~h}$ for growth arrest and treated with osteogenic differentiation medium, containing DMEM; 10\% FBS, L-glutamine, and $0.1 \mu \mathrm{M}$ dexamethasone; $10 \mathrm{mM} \beta$-glycerophosphate; $50 \mu \mathrm{M}$ L-ascorbic acid; and antibiotic (PG/S/AmB), all from Sigma, for a period of $21 \mathrm{~d}$. The medium was changed every $3 \mathrm{~d}$. Mineral deposition by ADSC, indicating early stages of bone formation, was visualized by Alizarin Red S staining with $\mathrm{pH}$ 4.2. Finally, the medium was removed and cells were washed with PBS followed by fixation in $10 \%(v / v)$ neutral buffered formalin for $30 \mathrm{~min}$, stained with Alizarin Red S solution (prepared according to the manufacturer's instructions) for $45 \mathrm{~min}$, and rinsed with dd $\mathrm{H}_{2} \mathrm{O}$ several times. Then images were taken. The extracellular calcium deposits, indicating early stages of bone formation, were stained in bright orange-red. 
Chondrogenic differentiation Chondrogenesis was performed as "pellet" culture system (Bosnakovski et al. 2004) by centrifugation of cells at a density of $2 \times 10^{5} / \mathrm{ml}$ at $400 \mathrm{~g}$ for $10 \mathrm{~min}$. The cells were expanded further into centrifuge tubes under humidified $5 \% \mathrm{CO}_{2}$ conditions at $38^{\circ} \mathrm{C}$ and treated with serum-free basal medium, supplemented with $10 \mathrm{ng} / \mathrm{ml}$ TGF $\beta-1$ (R\&D Systems, Inc., Minneapolis, MN), $0.1 \mu \mathrm{M}$ dexamethasone, and $50 \mu \mathrm{M}$ L-ascorbic acid. The medium was changed every third day for a $21-d$ period. The cells were fixed in $10 \%(v / v)$ neutral buffered formalin for $1 \mathrm{~h}$, washed twice with PBS, stained for $2 \mathrm{~h}$ in Alcian blue, treated with $0.1 \mathrm{M} \mathrm{HCl}$ for $5 \mathrm{~min}$, and double-washed with PBS. The samples were embedded in Entellan and pictures were taken.

Negative controls (NC) Fibroblasts obtained from rabbit kidney were used as negative controls during the adipogenic, osteogenic, and chondrogenic differentiation.

Statistical analysis Statistical calculations and the least significant digit (LSD) test were performed to determine the mean values, standard error of the mean (SEM), and significant differences observed in the samples after each adipose induction cycle, and AIPs were evaluated by Statistica v. 6.1 (StatSoft Inc., 2002).

\section{Results}

The OD values of eluted intracellular ORO-stainable lipids increased gradually during the whole experimental period in both controls and induced cell groups from all cell types (Fig. 2). At the end of the first induction cycle, significant differences between induced and their relevant controls were found only in directly seeded cell groups from subcutaneous $(0.356$ vs $0.446, p<0.01)$ and visceral $(0.314$ vs 0.377 , $p<0.05)$ fat depots. After the second cycle of induction, this dependency diminished for the cells of visceral fat depot, but appeared in the subcutaneous supernatant group ( 0.416 vs $0.468, p<0.05$ ) and remained for the subcutaneous primary isolated ADSC at the highest level of significance $(0.429$ vs $0.518, p<0.001)$. The last two dependencies were observed in the same proportions after the third induction cycle in both primary isolates of subcutaneous $(0.565$ vs $0.802, p<0.001)$ and their supernatants $(0.565$ vs $0.659, p<0.05)$ as well.
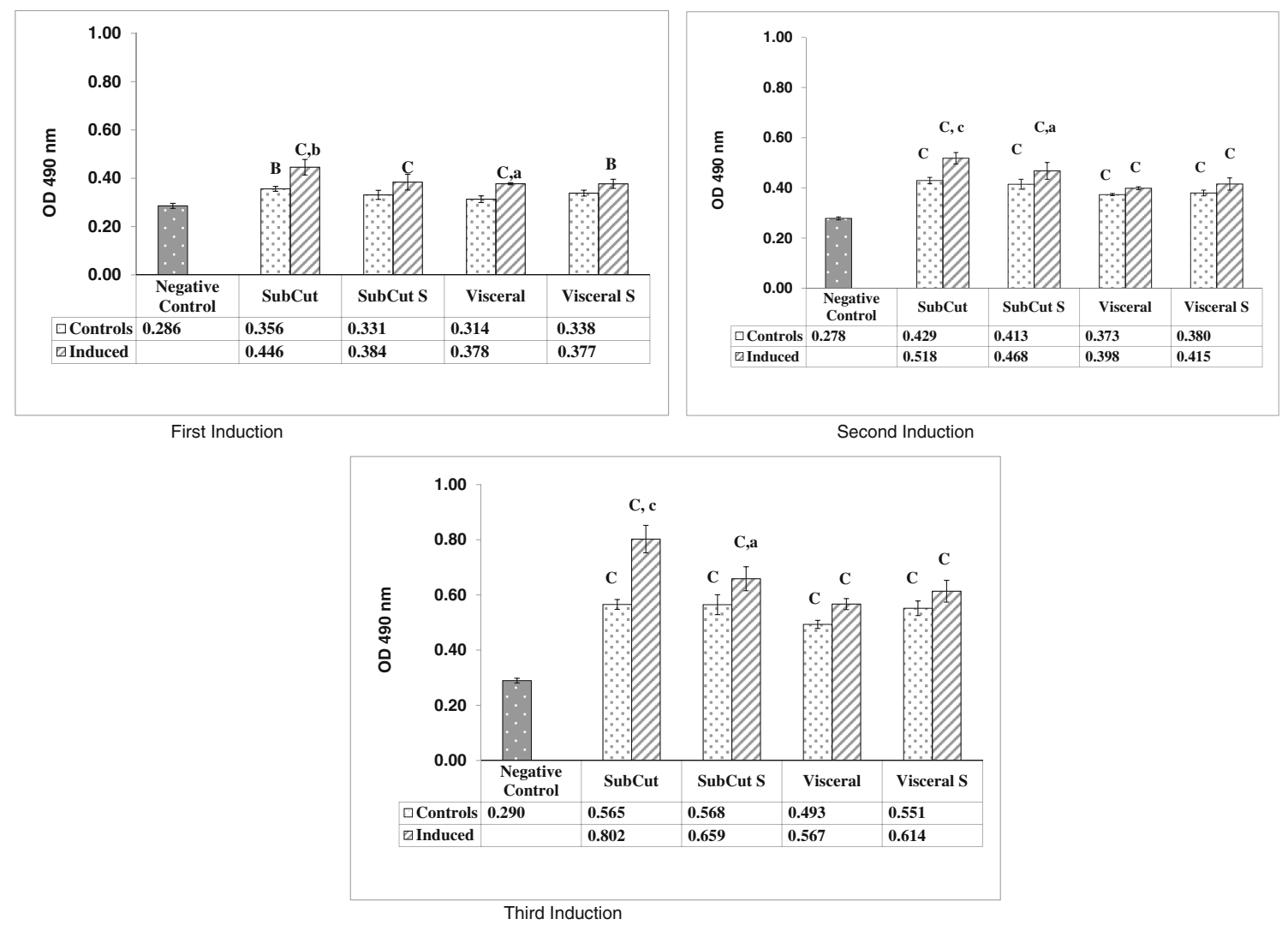

Figure 2 The level of accumulated Oil Red O-stained intracellular lipid droplets during the first, second, and third induction cycle, represented as mean group OD value of isopropanol extractions measured at $490 \mathrm{~nm}$.

Significances: to the NC: $A, B, C$; controls to induced for each group: $a, b$, $c ;(A$, a $p<0.05 ; B, b p<0.01 ; C, c p<0.001)$. Error bars indicate standard error of the mean. 
Our microscopic observations established that the ADSC from supernatant groups were morphologically closer to the non-induced controls than the other ones. When the number of inductions was increased, primary isolated ADSC from both subcutaneous and visceral fat depots showed the ability to form visible intracellular lipid filled compartments (Fig. 3A), but their supernatants did not. The directly seeded visceral fat cells reveal a well-visible capability to merge smaller lipid droplets into bigger ones in comparison to the subcutaneous cells (Fig. 3C).

Concerning the whole induction period, the OD values of eluted intracellular ORO-stainable lipids increased 1.80 times for the primary isolated subcutaneous cells, 1.72 times for their supernatants, 1.50 times for primary isolated visceral cells, and 1.63 times for the relevant supernatants. At the end of the first induction (Fig. 4), logically and following the previous exposed data, the highest rate of adipogenic ability was observed in directly seeded cells isolated from subcutaneous (25\%) and visceral (22\%) fat depots. After the second induction cycle, a process of depression of adipogenesis was observed in all groups, but it was highly expressed in directly seeded ADSC from visceral fat depots and their supernatants. Only the cells from the directly seeded subcutaneous group seemed to recover successfully, and after the third induction cycle, their adipogenic ability increased significantly up to $43 \%$ compared to the properties of the same cell types during the first $(p<0.05)$ and second $(p<0.05)$ induction. Although the mean OD values of the rest of the induced groups rose with the increasing number of inductions, neither the differences to their relevant controls nor the AIP within any other groups were statistically significant. Supernatants did not reach induction OD levels and adipogenic potential of their relevant precursors but followed the same pattern in both subcutaneous and visceral ADSC. However, the trend of induction in subcutaneous and visceral ADSC was opposite.

(A)

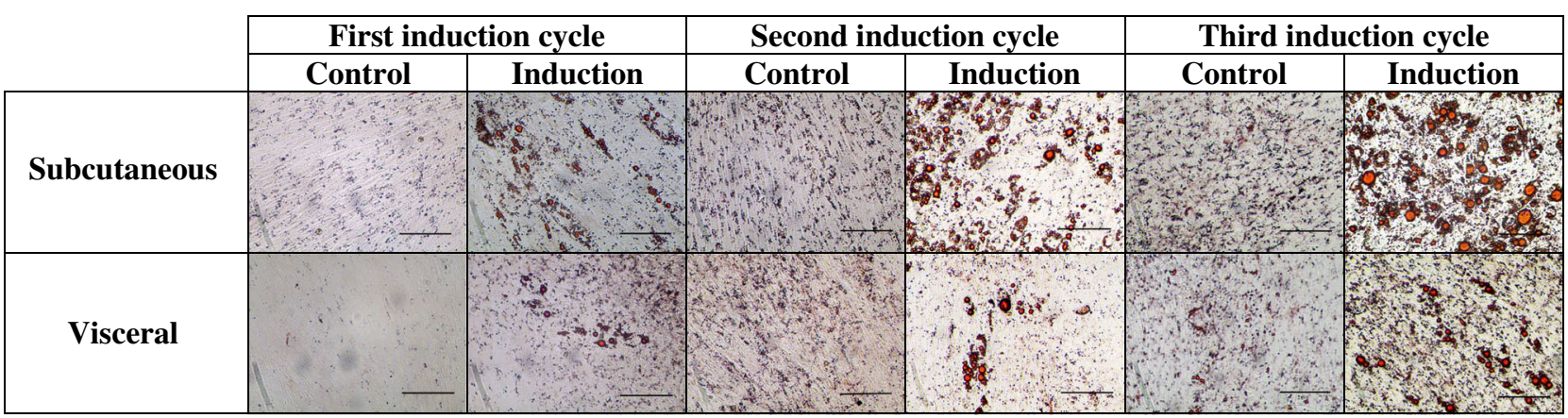

(B)

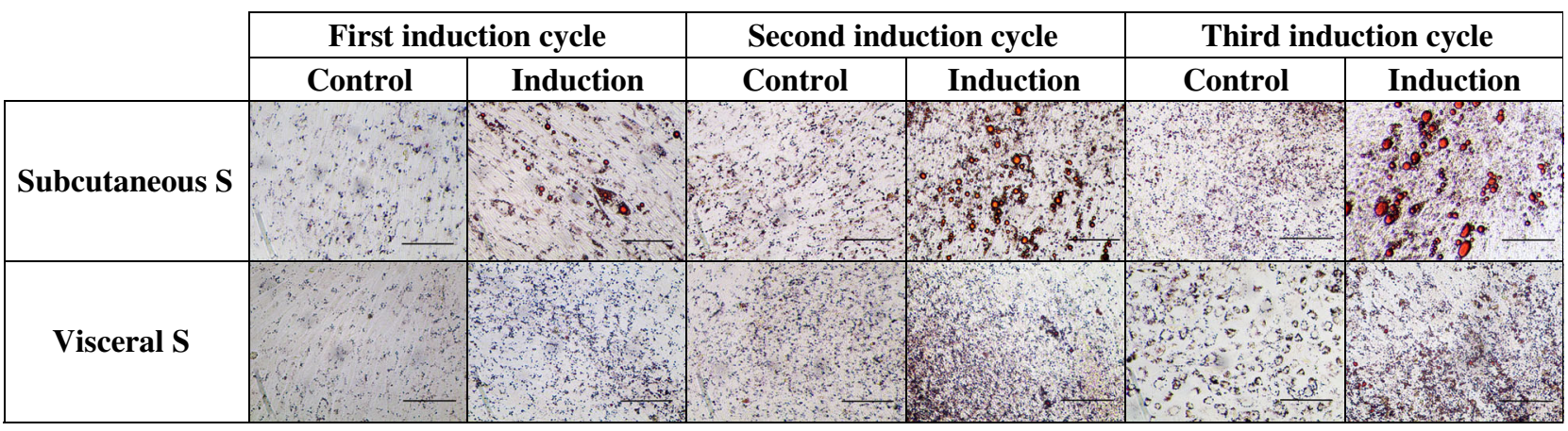

(C)

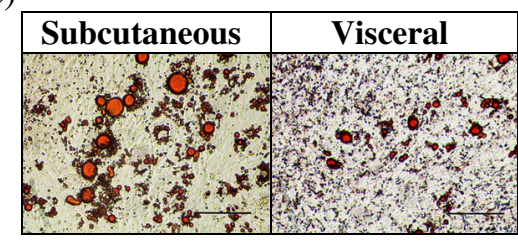

Figure 3 Oil Red O-stained non-induced (controls) and induced ADSC after the first, second, and third induction cycle. $(A)$ Direct seeded ADSC from subcutaneous and visceral fat depots. $(B)$ Supernatants of ADSC from subcutaneous and visceral fat depots. (C) Comparison of Oil Red Ostained direct seeded subcutaneous and visceral ADSC after the third induction cycle. Scale bars $200 \mu \mathrm{m}(A, B, C)$. 
Figure 4 The mean adipose induction potential (AIP) as percentage of OD values between induced and their relevant controls (considered as 100\%) for each induced group and each inducing cycle with trend lines. The panels represent plotted data referring direct seeded cells (in upper panel) and their relevant supernatants (in lower panel). Significances $(A, a p<0.05)$ : third to first (capital letter) and third to second induction cycles. Error bars indicate standard error of the mean.

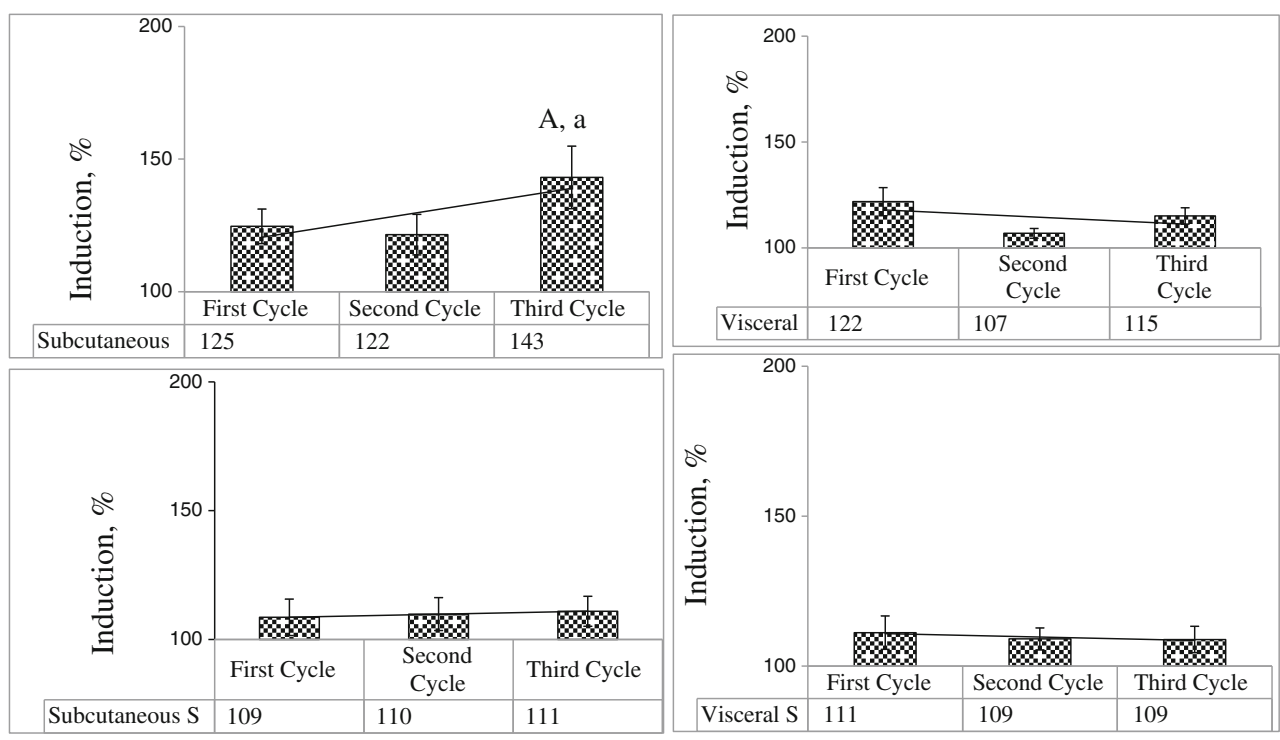

The fibroblasts obtained from kidney and used as negative controls did not show ability to accumulate intracellular OROstainable lipids. During the adipogenic induction, the differences of their OD mean values were considered insignificant (Fig. 5).

Excepting the fibroblasts, all isolated cell types demonstrated functional plasticity, which is proved by successfully performed osteogenic and chondrogenic differentiation, and could assume their multipotent properties (Fig. 6).

\section{Discussion}

Sugihara et al. (1986) proposed a method termed "ceiling culture" for culturing in vitro unilocular fat cells obtained from humans and rats. In this protocol, floating unilocular mature adipocytes adhere to the top inner surface of a culture flask filled completely with medium. This cell fraction, known as dedifferentiated fat (DFAT) cells (Nobusue et al. 2008), is abundant, homogenous, could be re-differentiated into mature adipocytes (Matsumoto et al. 2008), and exhibits multilineage potential in vitro (Matsumoto et al. 2008; Shen et al. 2011). In our study, the supernatants showed closer functional properties to the reported DFAT cells than to the floating ones. These results demonstrate that even though the mean OD levels increase with time laps, significant differences within induced and control groups were not observed. An increased lipid synthesis in induced supernatants and control groups was found during the experiment. These changes were not accompanied by increased ability to merge smaller lipid droplets into bigger ones, which is the main sign for differentiated adipocytes. Supernatants did not reach induction OD levels and adipogenic potential of their relevant precursors but follow the same pattern in both subcutaneous and visceral ADSC. In humans for example, it has been established that the subcutaneous DFAT cells do not express adipocyte markers such as lipoprotein lipase (LPL), leptin, glucose transporter-4 (GLUT-4), and C/EBP-a, showing low levels of PPAR $\gamma, \mathrm{C} /$ EBP-b, and C/EBP-d transcripts (Matsumoto et al. 2008). Moreover, these cells express critical factors for osteogenesis and chondrogenesis, such as RUNX2 and SOX9, respectively, and are able to undergo osteogenic and chondrogenic differentiation in vitro in the presence of appropriate culture conditions (Matsumoto et al. 2008). The isolated cells in our study showed functional plasticity which was expressed by

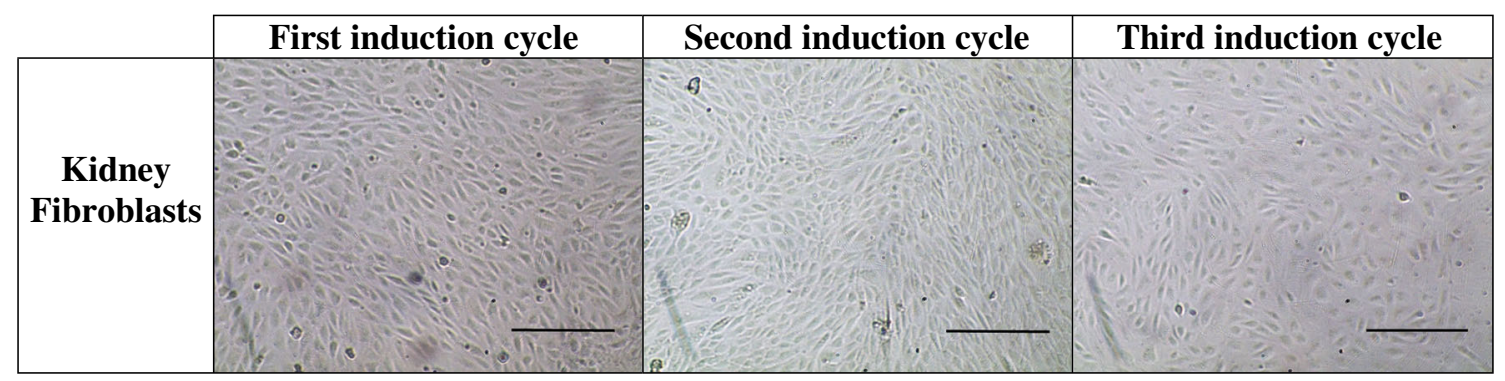

Figure 5 Oil Red O-stained kidney fibroblast after the first, second, and third induction cycle Scale bars $200 \mu \mathrm{m}$. 


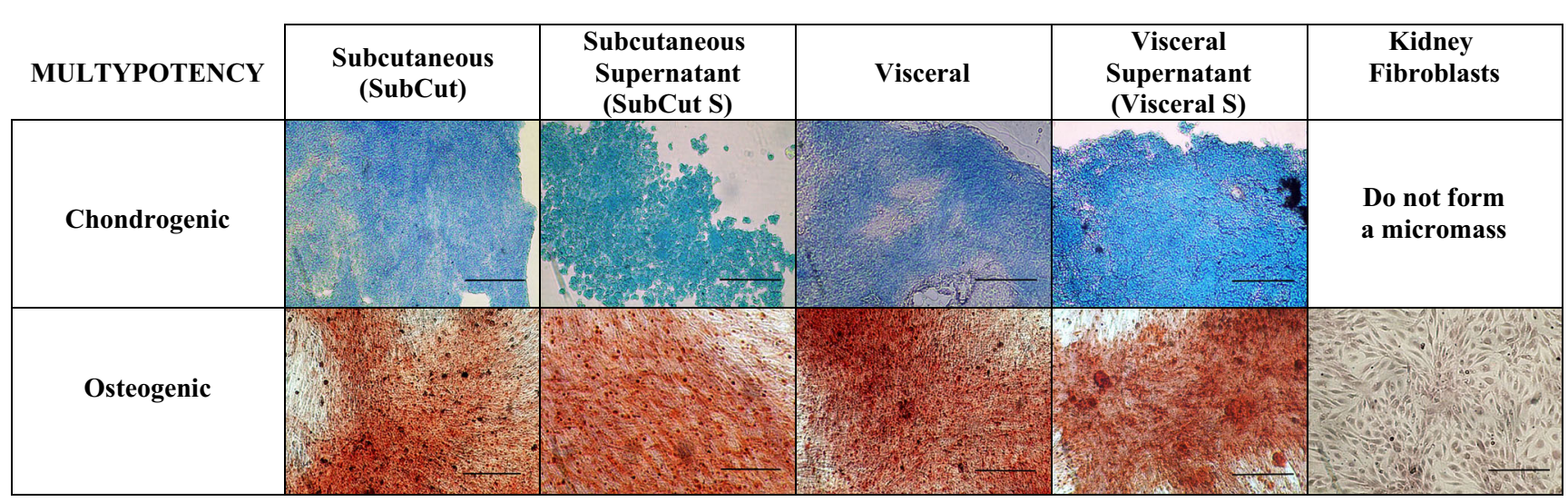

Figure 6 Functional multipotency of each isolated ADSC type: for osteogenesis, the samples were stained with Alcian blue, scale bars 350 um; for chondrogenesis, the samples stained with Alizarin Red, scale bars $200 \mu \mathrm{m}$.

successfully performed osteogenic and chondrogenic differentiation. These results confirmed the findings that primary cells and their supernatants have similar potential for differentiation along the mesenchymal lineage to produce adipocytes, osteoblasts, and chondrocytes (Miyazaki et al. 2005). In this context, the supernatant cells in the current experiment had functional properties closer to the DFAT cells reported by Buschmann et al. (2013) rather than floating cells. A possible explanation of that finding could be lack of the specific adipocyte gene expression mentioned above, but such a hypothesis should be investigated by additional study.

Traditional protocols for adipogenic induction propose a hormonal cocktail of insulin, dexamethasone (DXM), and IBMX, in order to differentiate preadipocytes into mature adipocyte cells (Gregoire et al. 1998; Farmer 2006). In the current study, we found that the inducing media cause changes in quantity as opposed to morphological changes in visceral cells. Even though induction was triplicated, those cells neither deployed their adipogenic potential nor showed typical signs of mature adipocytes, i.e., the spontaneous adipogenesis in controls was in a range closer to the induced ones. Dexamethasone and IBMX are known as powerful inductors of adipogenesis at early stages of differentiation (Caprio et al. 2007; Moreno-Navarrete and Fernández-Real 2012). In contrast, insulin alone is required to continue the differentiation program (Moreno-Navarrete and Fernández-Real 2012), to increase the number of differentiated cells (Suryawan et al. 1997). Therefore, it was defined as the major regulator of the above-mentioned process (Klemm et al. 2001). Furthermore, during the terminal phase of differentiation, adipocytes in culture markedly increase de novo lipogenesis and acquire sensitivity to insulin. Depending on the culture system, the insulin/IGF-I signaling pathway may be either critical for differentiation or necessary only to achieve the maximal rate of triacylglycerol accumulation that accompanies adipocyte differentiation (Gregoire et al. 1998). Furthermore, adding dexamethasone at later stages of adipose maturation has rather adipogenic effects, which is indicative of their strictly time-dependent manner of action (Caprio et al. 2007). Our data allows us to conclude that the application of insulin without other inducers during the second and third induction cycle could be more effective for successful adipogenesis in primary isolated rabbit visceral ADSC. This idea should be experimentally investigated in further studies.

The size of the lipid droplets depends on the expression of two proteins, Cidea and perilipin (a lipid droplet scaffold protein), which regulate the activity of lipolytic enzymes and are responsible for the TG removal out of the cell as well (Brasaemle et al. 2000; Puri et al. 2008). Perilipin and Cidea are down-regulated at the transcriptional level by PPAR $\gamma$, demonstrating the importance of this mechanism during the formation and growth of lipid droplets into adipocytes (Arimura et al. 2004; Viswakarma et al. 2007). Based on the achieved results, we suspect lack of activation of PPAR $\gamma$ for visceral and their relevant supernatant groups, which in turn lower their adipogenic potential. Besides, in our parallel study, the qPCR data showed significantly reduced PPAR $\gamma$ gene expression after the third induction in visceral than in subcutaneous directly seeded cells (preliminary unpublished results).

Obviously, the proposed triplicated induction protocol did not significantly affect the adipogenic potential of the directly seeded and supernatant visceral cells. We suspect a different way of adipogenesis activation in those cell types. Recently, Ong et al. (2014) reported that high expression of CD200 in ADSC obtained from visceral fat correlates with low adipogenic capacities in humans and mice. CD200, also called $\mathrm{OX} 2$, is a member of the immunoglobulin superfamily of proteins, and its expression is related to various immunoregulatory activities such as cancer growth, autoimmune and allergic disorders, infection, etc. (Gorczynski 2012). Possibly, a different manner of adipose differentiation between subcutaneous and visceral ADSC affecting their adipogenic ability in vitro and the developing of inflammatory or autoimmune response could explain the achieved results in the current study, but this hypothesis should be verified in a future study. For 
this reason, we consider that the proposed model is not appropriate for in vitro studies at a molecular level in cells achieved from visceral fat depots. The finding that increased induction numbers did not improve significantly the adipogenic potential of visceral fat cells supports that statement.

Actually, a real induction is observed only in the subcutaneous group, which confirms the data reported by Djian et al. (1983). The authors notified that subcutaneous ADSC replicate and differentiate better than visceral ADSC, and those abilities are clearly influenced by the anatomic site of the depot origin. Since the anatomical and histological observations showed that in blood vessels interscapular fat depots are more numerous and better developed than those in perirenal depots (Yonkova 2014), it seems logical that the isolated cell fraction would be more enriched in stromal-vascular cells. Those cells have been shown to reside in a perivascular location, and ADSC may in fact be vascular stem cells (VSC) (Lin et al. 2010). This statement is very plausible and explains why the multipotent cells isolated from subcutaneous fat depot can give rise to several cell lineages such as adipocytes, osteoblasts, and chondrocytes; why they are abundant; and why they show better multifunctional plasticity and are identified by numerous authors as a prospective cell source for autologous transplantation in regenerative medicine (Tran and Kahn 2010; Sunay et al. 2013).

In general, the adipose differentiation abilities of the primary isolates from subcutaneous fat depots definitely have advantages over the visceral and both supernatants.

\section{Conclusions}

In general, depending on isolation method, the directly seeded cells from both subcutaneous and visceral originated cells have better adipose differentiation potential than their relevant supernatants. Increasing the numbers of applied inductions suppresses adipogenesis at the second cycle. These compounds significantly potentiated it only in directly seeded cells from subcutaneous ADSC after completing the third induction cycle. Based on the experimentally achieved data and its subsequent analysis, the cell fraction isolated from directly seeded subcutaneous SVF showed the best adipose differentiation potential.

\footnotetext{
Acknowledgments Project 4/13 within Trakia University-FVM; Short Term Scientific Mission within COST Action TD1101-RGB-Net-Dr. Darko Bosnakovski; Central Scientific and Research Laboratory, Trakia University; and Boyana Rashkova - student in Trakia University-FVM, are acknowledged.
}

\section{References}

Aguilera CM, Ramirez-Tortosa MC, Mesa MD, Ramirez-Tortosa CL, Gil A (2002) Sunflower, virgin-olive and fish oils differentially affect the progression of aortic lesions in rabbits with experimental atherosclerosis. Atherosclerosis 162:335-344

Ailhaud G (2006) Adipose tissue as a secretory organ: from adipogenesis to the metabolic syndrome. C R Biol 329(8):570-577

Arimura N, Horiba T, Imagawa M, Shimizu M, Sato R (2004) The peroxisome proliferator-activated receptor gamma regulates expression of the perilipin gene in adipocytes. J Biol Chem 279(11):1007010076

Bosnakovski D, Mizuno M, Kim G, Ishiguro T, Okumura M, Iwanaga T, Kadosawa T, Fujinaga T (2004) Chondrogenic differentiation of bovine bone marrow mesenchymal stem cells in pellet cultural system. Exp Hematol 32:502-509

Bosnakovski D, Mizuno M, Kim G, Takagi S, Okumura M, Fujinaga T (2005) Isolation and multilineage differentiation of bovine bone marrow mesenchymal stem cells. Cell Tissue Res 319:243-253. doi:10.1007/s00441-004-1012-5

Bourin P, Bunnell BA, Casteilla L, Dominici M, Katz AJ, March KL, Redl H, Rubin JP, Yoshimura K, Gimble JM (2013) Stromal cells from the adipose tissue-derived stromal vascular fraction and culture expanded adipose tissue-derived stromal/stem cells: a joint statement of the International Federation for Adipose Therapeutics and Science (IFATS) and the International Society for Cellular Therapy (ISCT). Cytotherapy 15(6):641-648. doi:10.1016/j.jcyt.2013.02. 006

Brasaemle DL, Rubin B, Harten IA, Gruia-Gray J, Kimmel AR, Londos C (2000) Perilipin A increases triacylglycerol storage by decreasing the rate of triacylglycerol hydrolysis. J Biol Chem 275(49):3848638493

Buschmann J, Gao S, Härter L, Hemmi S, Welti M, Werner CM, Calcagni M, Cinelli P, Wanner GA (2013) Yield and proliferation rate of adipose-derived stromal cells as a function of age, body mass index and harvest site-increasing the yield by use of adherent and supernatant fractions. Cytotherapy 15(9):1098-1105. doi:10.1016/j.jcyt. 2013.04.009, Epub 2013 Jun 22

Caprio M, Fève B, Claës A, Viengchareun S, Lombès M, Zennaro MC (2007) Pivotal role of the mineralocorticoid receptor in corticosteroid-induced adipogenesis. FASEB J 21:2185-2194

Cawthorn WP, Scheller EL, MacDougald OA (2012) Adipose tissue stem cells meet preadipocyte commitment: going back to the future. $\mathrm{J}$ Lipid Res 53:227-246

Choi YS, Vincent LG, Lee AR, Dobke MK, Engler AJ (2012) Mechanical derivation of functional myotubes from adiposederived stem cells. Biomaterials 33:2482-2491

Djian P, Roncari AK, Hollenberg CH (1983) Influence of anatomic site and age on the replication and differentiation of rat adipocyte precursors in culture. J Clin Invest 72:1200-1208

Dodson MV, Mir PS, Hausman GJ, Guan LL, Du M, Jiang Z, Fernyhough ME, Bergen WG (2011) Obesity, Metabolic Syndrome, and Adipocytes. Journal of Lipids, Article ID 721686, doi: $10.1155 / 2011 / 721686$

Farmer SR (2006) Transcriptional control of adipocyte formation. Cell Metab 4:263-273

Georgiev IP, Georgieva TM, Ivanov V, Dimitrova S, Kanelov I, Vlaykova T, Tanev S, Zaprianova D, Dichlianova E, Penchev G, Lazarov L, Vachkova E, Roussenov A (2011) Effects of castration-induced visceral obesity and antioxidant treatment on lipid profile and insulin sensitivity in New Zealand white rabbits. Res Vet Sci 90(2):196204. doi:10.1016/j.rvsc.2010.05.023

Gorczynski RM (2012) CD200:CD200R-mediated regulation of immunity. ISRN Immunol 2012:1-18. doi:10.5402/2012/682168 
Gregoire FM, Smas CM, Sul HS (1998) Understanding adipocyte differentiation. Physiol Rev 78:783-809

Han J, Koh YJ, Moon HR, Ryoo HG, Cho CH, Kim I, Koh GY (2010) Adipose tissue is an extramedullary reservoir for functional hematopoietic stem and progenitor cells. Blood 115:957-964

Hausman GJ, Dodson MV (2012) Stromal vascular cells and adipogenesis: cells within adipose depots regulate adipogenesis. J Genom 1: 56-66. doi:10.7150/jgen.3813

Katz AJ (2002) Mesenchymal cell culture: adipose tissue. Atala A \& Lanza R, editors. Methods of Tissue Engineering. Academic Press, 277-286

Klemm DJ, Leitner JW, Watson P, Nesterova A, Jane E, Reusch B, Goalstone ML, Draznin B (2001) Insulin-induced adipocyte differentiation: activation of CREB rescues adipogenesis from the arrest caused by inhibition of prenylation. J Biol Chem 276:28430-28435

Lin CS, Xin ZC, Deng CH, Ning H, Lin G, Lue TF (2010) Defining adipose tissue-derived stem cells in tissue and in culture. A perivascular origin for mesenchymal stem cells in multiple human organs. Histol Histopathol 25(6):807-815

Lowe CE, O'Rahilly S, Rochford JJ (2011) Adipogenesis at a glance. J Cell Sci 124:2681-2686. doi:10.1242/jcs.079699

Matsumoto T, Kano K, Kondo D, Fukuda N, Iribe Y, Tanaka N, Matsubara Y, Sakuma T, Satomi A, Otaki M, Ryu J, Mugishima H (2008) Mature adipocyte-derived dedifferentiated fat cells exhibit multilineage potential. J Cell Physiol 215:210-222. doi:10.1002/ jcp. 21304

Mitchell JB, McIntosh K, Zvonic S, Garrett S, Floyd ZE, Kloster A, Di Halvorsen Y, Storms RW, Goh B, Kilroy G, Wu X, Gimble JM (2006) Immunophenotype of human adipose derived cells: temporal changes in stromal - and stem cell-associated markers. Stem Cells $24: 376-385$

Miyazaki T, Kitagawa Y, Toriyama K, Kobori M, Torii S (2005) Isolation of two human fibroblastic cell populations with multiple but distinct potential of mesenchymal differentiation by ceiling culture of mature fat cells from subcutaneous adipose tissue. Differentiation 73: 69-78. doi:10.1111/j.1432-0436.2005.07302004

Monaco E, Bionaz M, Hollister SJ, Wheeler MB (2011) Strategies for regeneration of the bone using porcine adultadipose-derived mesenchymal stem cells. Theriogenology 75:1381-1399

Moreno-Navarrete JM, Fernández-Real JM (2012) Adipocyte differentiation. In: Symonds ME (ed) Adipose tissue biology. Springer Science + Business Media, New York, pp 17-38. doi:10.1007/ 978-1-4614-0965-6 2

Nobusue H, Endo T, Kano K (2008) Establishment of a preadipocyte cell line derived from mature adipocytes of GFP transgenic mice and formation of adipose tissue. Cell Tissue Res 332:435-446

Ong WK, Tan CS, Chan KL, Goesantoso GG, Chan XH, Chan E, Yin J, Yeo CR, Khoo CM, So JB, Shabbir A, Toh SA, Han W, Sugii S (2014) Identification of specific cell-surface markers of adiposederived stem cells from subcutaneous and visceral Fat depots. Stem Cell Rep 2(2):171-179. doi:10.1016/j.stemcr.2014.01.002

Perrini S, Ficarella R, Picardi E, Cignarelli A, Barbaro M, Nigro P, Peschechera A, Palumbo O, Carella M, De Fazio M, Natalicchio A, Laviola L, Pesole G, Giorgino F (2013) Differences in gene expression and cytokine release profiles highlight the heterogeneity of distinct subsets of adipose tissue-derived stem cells in the subcutaneous and visceral adipose tissue in humans. PLoS ONE 8(3):57892. doi:10. 1371/journal.pone.0057892

Puri V, Ranjit S, Konda S, Nicoloro SM, Straubhaar J, Chawla A, Chouinard M, Lin C, Burkart A, Corvera S (2008) Cidea is associated with lipid droplets and insulin sensitivity in humans. PNAS 105(22):7833-7838
Reyne Y, Nouguès J, Dulor JP (1989) Differentiation of rabbit adipocyte precursor cells in a serum-free medium. In Vitro Cell Dev Biol 25: $747-752$

Rodeheffer MS, Birsoy K, Friedman JM (2008) Identification of white adipocyte progenitor cells in vivo. Cell 135:240-249

Shen JF, Sugawara A, Yamashita J, Ogura H, Sato S (2011) Dedifferentiated fat cells: an alternative source of adult multipotent cells from the adipose tissues. Int J Oral Sci 3(3):117-124. doi:10. 4248/IJOS11044

Sugihara H, Yonemitsu N, Miyabara S, Yun K (1986) Primary cultures of unilocular fat cells: characteristics of growth in vitro and changes in differentiation properties. Differentiation 31:42-49

Sunay O, Can G, Cakir Z, Denek Z, Kozanoglu I, Erbil G, Yilmaz M, Baran Y (2013) Autologous rabbit adipose tissue-derived mesenchymal stromal cells for the treatment of bone injuries with distraction osteogenesis. Cytotherapy 15(6):690-702

Suryawan A, Swanson LV, Hu CY (1997) Insulin and hydro- cortisone, but not triiodothyronine, are required for the differentia tion of pig preadipocytes in primary culture. J Anim Sci 75:105-111

Tang W, Zeve D, Suh JM, Bosnakovski D, Kyba M, Hammer RE, Tallquist MD, Graff JM (2008) White Fat progenitor cells reside in the adipose vasculature. Science 322(5901):583-586. doi:10. 1126/science. 1156232

Tran T, Kahn C (2010) Transplantation of adipose tissue and stem cells: role in metabolism and disease. Nat Rev Endocrinol 6(4):195-213

Trayhurn P, Beattie JH (2001) Physiological role of adipose tissue: white adipose tissue as an endocrine and secretory organ. Proc Nutr Soc 60(3):329-339

Vignozzi L, Morelli A, Filippi S, Comeglio P, Chavalmane AK, Marchetta M, Toce M, Yehiely-Cohen R, Vannelli GB, Adorini L, Maggi M (2011) Farnesoid X receptor activation improves erectile function in animal models of metabolic syndrome and diabetes. J Sex Med 8:57-77

Viswakarma N, Yu S, Naik S, Kashireddy P, Matsumoto K, Sarkar J, Surapureddi S, Jia Y, Rao MS, Reddy JK (2007) Transcriptional regulation of Cidea, mitochondrial cell death-inducing DNA fragmentation factor alpha-like effector a, in mouse liver by peroxisome proliferatoractivated receptor alpha and gamma. J Biol Chem 282(25):18613-18624

Wozniak SE, Gee LL, Wachtel MS, Frezza EE (2009) Adipose tissue: the new endocrine organ? A review article. Digest Dis Sci 54(9):18471856

Yang XF, He X, He J, Zhang LH, Su XJ, Dong ZX, Xu YJ, Li Y, Li YL (2011a) High efficient isolation and systematic identification of human adipose-derived mesenchymal stem cells. J Biomed Sci 18:59 (b)

Yang MT, Fu J, Wang Y, Desai RA, Chen CS (2011b) Assaying stem cell mechanobiology on microfabricated elastomeric substrates with geometrically modulated rigidity. Nat Protoc 6:187-213. doi:10. 1038/nprot.2010.189

Yanni AE (2004) The laboratory rabbit: an animal model of atherosclerosis research. Lab Anim 38:246-256

Yonkova P (2014) Morphological investigations on fat depots in New Zealand white rabbits. PhD Thesis, Stara Zagora

Zheng B, Cao B, Li G, Huard J (2006) Mouse adipose-derived stem cells undergo multilineage differentiation in vitro but primarily osteogenic and chondrogenic differentiation in vivo. Tissue Eng 12:18911901

Zuk PA, Zhu M, Mizuno H, Huang J, Futrell JW, Katz AJ, Benhaim P, Lorenz HP, Hedrick MH (2001) Multilineage cells from human adipose tissue: implications for cell-based therapies. Tissue Eng 7: 211-228

Zuk PA, Zhu M, Ashjian P, De Ugarte DA, Huang J, Mizuno H, Alfonso ZC, Fraser JK, Benhaim P, Hedrick MH (2002) Human adipose tissue is a source of multipotent stem cells. Mol Biol Cell 13: 4279-4295 